\title{
Espacios en disputa: universidades, conflicto y polarización política
} en Nicaragua

\section{Resumen}

Este artículo se propone examinar las protestas que tuvieron lugar en Nicaragua, entre abril y junio de 2019, en contra del gobierno de Daniel Ortega y Rosario Murillo y la respuesta represiva por parte del Estado, centrando el análisis en el espacio universitario y la acción colectiva estudiantil. Con base en la reconstrucción de los vínculos entre sandinismo, movimiento estudiantil y universidades, así como el papel de la organización estudiantil oficial Unión Nacional de Estudiantes Nicaragüenses (UNEN) para monopolizar la representación gremial en beneficio del partido gobernante, el artículo pretende contextualizar las confrontaciones violentas entre, por un lado, fuerzas policiales, parapoliciales y grupos de choque pro-gubernamentales y, por otro parte, jóvenes de diversos orígenes sociales y educativos. Se señala que la polarización entre sandinismo y antisandinismo que se impuso en el conflicto sociopolítico de 2018 es uno de los aspectos claves a tomar en cuenta para entender con más precisión las lógicas de movilización, el uso de la violencia por grupos civiles pro- y antigubernamentales y el uso desmedido de la fuerza policial para desarticular las protestas.

Palabras clave: Sandinismo, Anti-sandinismo, Movimiento estudiantil, Daniel Ortega, Nicaragua

\section{Abstract}

This paper aims to examine the protests against the government of Daniel Ortega and Rosario Murillo that took place in Nicaragua between April and June 2019 , as well as the repressive reaction of the State by focusing the analysis on universities and students as important participants of the mobilizaton. It seeks to contextualize the violent confrontations beween police and parapolice forces, on the one hand, and young people of different educational and social origins, on the other, by highlighting the links between Sandinismo, student movement and universities, as well as the role of the oficial student organization National Union of Nicaraguan Students (UNEN) in the monopolization of representation for the benefit of the FSLN. The article points out that the ideological polarization between Sandinismo and Anti-sandinismo which quickly dominated de protests of 2018 in Nicaragua is also one of the key aspects to take into account in order to understand more precisely the logics of mobilization, the use of violence by pro- and anti-governmental civils and the excessive use of the police force to disrupt these protests.

Keywords: Sandinismo, Anti-sandinismo, Student movement, Daniel Ortega, Nicaragua

POR KRISTINA PIRKER. Estudios de Sociología y Ciencias Políticas en la Universidad de Viena (Austria), Doctora en Estudios Latinoamericanos por la UNAM. Profesora-investigadora del Instituto de Investigaciones Dr. José María Luis Mora y profesora de asignatura del Colegio de Estudios Latinoamericanos/Facultad de Filosofía y Letras/UNAM. Sus líneas de investigación son Movimientos sociales y partidos políticos en Centroamérica; Activismo trasnacional en México y Centroamérica; Violencia política en América Latina. kpirker@institutomora.edu.mx 


\section{Introducción ${ }^{1}$}

Dentro y fuera de Nicaragua, todos -analistas políticos, académicos e incluso el gobierno de Daniel Ortega y Rosario Murillo- fueron tomados por sorpresa cuando en abril de 2018 las protestas antigubernamentales empezaron a extenderse. El proceso de movilización inició en Managua y León con pequeñas manifestaciones para denunciar las fallas gubernamentales en el control oportuno del incendio en la Reserva Biológica Indio Maíz en el sureste de Nicaragua. El acoso violento a los manifestantes -principalmente activistas ecologistas y estudiantes universitarios- por simpatizantes del partido gobernante Frente Sandinista de Liberación Nacional (FSLN) y su organización juvenil Juventud Sandinista (JS), bajo la mirada anuente de los cuerpos policiales, se difundió a través de las redes sociales generando una reacción de indignación social en diferentes segmentos de la población. El segundo momento se dio el 18 de abril, a raíz de la publicación en La Gaceta del decreto para reformar el Instituto Nicaragüense del Seguro Social (INSS), decisión tomada por el Ejecutivo de manera unilateral, sin haber llegado a un acuerdo con el empresariado agrupado en el Consejo Superior de la Empresa Privada (COSEP). ${ }^{2}$

Entre el 18 y 22 de abril de 2018, la indignación social con la intervención violenta de simpatizantes del gobierno y el uso desmedido de la fuerza por parte de policías y fuerzas antimotines en contra de los manifestantes, que produjeron heridos y el 19 de abril los primeros muertos, provocó una expansión geográfica de las protestas a ciudades como León, Masaya, Matagalpa, Estelí, Ocotal y Bluefields. Las protestas se radicalizaron, pasando de la acción cívica, no violenta, al uso de armamentos caseros (morteros, bombas molotov) y la quema de edificios sandinistas y gubernamentales, y de las demandas centradas en la revocación de las reformas al seguro social (derogadas por Daniel Ortega el 22 de abril) a la exigencia de justicia por los muertos y heridos, la renuncia de Daniel Ortega y Rosario Murillo y la conformación de un gobierno de transición. La marcha multitudinaria del 30 de mayo en apoyo a las madres y familiares de las víctimas de la violencia estatal, expresó claramente 
esta indignación compartida por amplios sectores de la sociedad nicaragüense (incluyendo sandinistas) y su solidaridad con los muertos y heridos, en su mayoría adolescentes. También esta marcha terminó en choques violentos entre simpatizantes gubernamentales y grupos de la oposición, con un saldo de 15 muertos y el incendio de la radio progubernamental Nueva Radio Ya por un grupo de manifestantes.

Desde el inicio de las manifestaciones se fueron construyendo dos narrativas para explicar el estallido tan repentino y radical y el alto grado de violencia de las mismas. Mientras para activistas, partidos de oposición y organizaciones nacionales e internacionales de derechos humanos se trataba de manifestaciones espontáneas y grupos "autoconvocados" para oponerse a una dictadura corrupta, excluyente y represiva, ${ }^{3}$ el gobierno del FSLN y sus aliados han planteado que se trató de un intento de golpe de Estado organizado por grupos radicales de la oposición política y apoyados por la ultraderecha estadounidense (López, 2018; Comisión de la Verdad, Justicia y Paz, 2018).

En vez de argumentar a favor de una u otra de las dos posiciones y reproducir de esta manera la polarización que caracteriza la sociedad nicaragüense, este artículo se propone analizar el impacto de la polarización en las universidades, como uno de los espacios donde el malestar anti-gubernamental se fue gestionando y expresando primeramente, así como la relación con las prácticas violentas en las confrontaciones dentro de las instalaciones universitarias y las manifestaciones donde los estudiantes fueron protagonistas. Porque, si bien la escalada violenta de las protestas fue indudablemente la consecuencia de la represión indiscriminada por parte de policías, fuerzas parapoliciales y grupos de choque vinculados al FSLN, el alto saldo de heridos y muertos durante todo el ciclo de protesta -entre ellos también policías, activistas sandinistas y trabajadores gubernamentales- revela la disposición de un grupo de manifestantes de recurrir a la violencia como método para radicalizar la protesta. La conexión entre polarización política y violencia colectiva que a lo largo del siglo veinte ha afectado la sociedad de este pequeño país centroamericano impide incluso hoy en día la construcción de un consenso respecto a
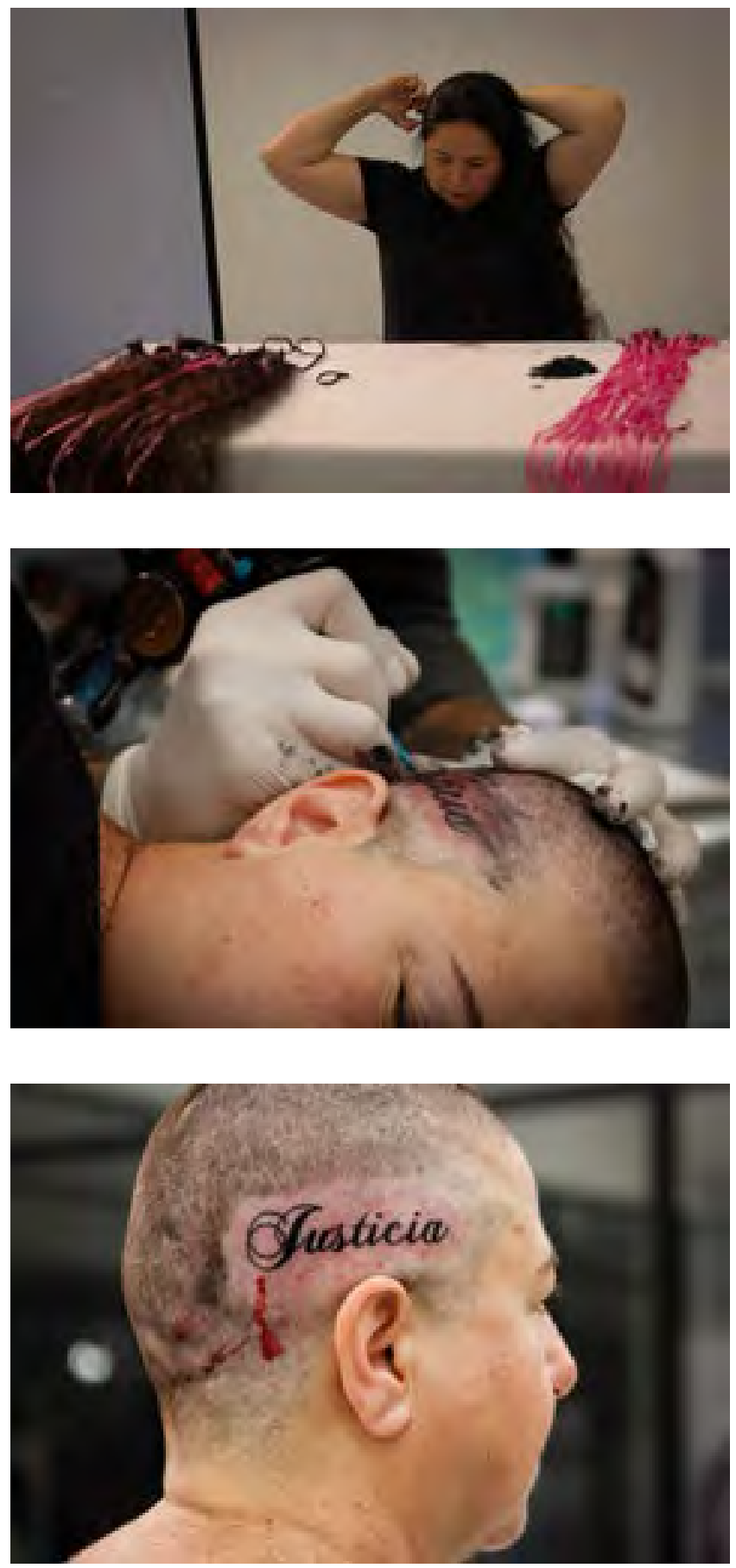

Elina Chauvet, Performance Mi Cabello Por tu Nombre, Culiacán, Sinaloa, México, 2014. 
la interpretación de los sucesos ocurridos entre abril y julio del 2018 y dificulta llegar a un acuerdo aceptable para todas las partes.

\section{La disputa por los muertos}

Las controversias empiezan por la caracterización de las protestas como "cívicas" o "violentas" y el número de muertos provocados directamente por la intervención gubernamental, ya que las víctimas mortales, los heridos y los actos de vandalismo corresponden no sólo a la acción policial, sino también a los choques entre grupos pro- y antigubernamentales -ambos conformados principalmente por adolescentes-, las acciones concertadas por grupos radicalizados de la oposición en contra de edificios públicos, locales partidarios y monumentos sandinistas, así como saqueos y violencia ejercida por personas aviadoras de las protestas, como habitantes de las colonias marginales y miembros de la delincuencia común.

\section{...los universitarios se han mantenido en el imaginario social como referentes de las protestas, con mucho más credibilidad que otros potenciales representantes de la oposición, como podrian ser las cámaras empresariales...}

De acuerdo a los primeros informes sobre las violaciones a los derechos humanos, en el contexto de las protestas en contra del gobierno de Ortega 109 muertos, solamente entre el 18 de abril y el 30 de mayo (Grupo Interdisciplinario de Expertos Independientes Nicaragua, 2018, pág. 71). En un Informe anterior, publicado por la Comisión Interamericana de Derechos Humanos en junio del 2018, entre el 18 de abril y el 19 de junio, se contabilizaron 212 víctimas mortales (Comisíon Interamericana de Derechos Humanos, 2018, pág. 28). Desde el inicio, el gobierno nicaragüense señaló estas cifras como demasiado elevadas, al sumar a personas que habían muerto bajo circunstancias ajenas al conflicto sociopolítico (por ejemplo, víctimas de la delincuencia común, accidentes, etcétera) y criticaba que se responsabilizaba primordialmente a los agentes gubernamentales y pro-gubernamentales, omitiendo de esta manera la identidad política sandinista de muchas víctimas. En este contexto de cuestionamientos mutuos de las cifras manejadas respectivamente por actores pro- $\mathrm{y}$ antigubernamentales, la Comisión de la Verdad de la Asamblea Legislativa publicó su informe, según el cual entre el 18 abril y el 30 de mayo habría 110, y hasta el 15 de octubre 269 víctimas mortales (Comisión de la Verdad, Justicia y Paz, 2018).

A pesar del sesgo progubernamental de la Comisión, las cifras del Informe arrojan datos interesantes sobre el perfil de las personas asesinadas. Así, el 32,7 por ciento del total de víctimas fatales, corresponde a personas entre 18 y 25 años y el 28,2 por ciento a personas entre 26 y 35 años. Casi en su totalidad -el 96 por ciento- fueron hombres jóvenes de origen obrero y popular: entre los muertos las tres categorías más numerosas son obreros (62 víctimas), trabajadores por cuenta propia (62) y desempleados (46), pero sólo se contabilizaron ocho estudiantes universitarios y seis estudiantes de secundaria (Comisión de la Verdad, Justicia y Paz, 2018).

El saldo de muertos y la virulencia de los choques evidencian la profundidad y complejidad de una confrontación sociopolítica, en la cual se articulan malestares con el gobierno del FSLN -agudizados por el autoritarismo y la soberbia de sus representantes en todos los niveles de gobierno-, traumas de la guerra contrarrevolucionaria de la década de 1980 , que nunca fueron atendidos, y resentimientos antisandinistas, actualizados y difundidos por medios de comunicación tradicionales, plataformas digitales y los mensajes en redes sociales que proliferaron durante los días de la protesta (Castro Iraheta, 2018, pág. 177ss). Aunque entre junio y julio el centro de la conflictividad se desplazó de los espacios universitarios y las marchas, hacia las vías de comunicación y los llamados "tranques", ${ }^{4}$ los universitarios se han mantenido en el imaginario social como referentes de las protestas, con mucho más credibilidad que otros potenciales representantes de la oposición, como podrían ser las cámaras empresariales -durante muchos 


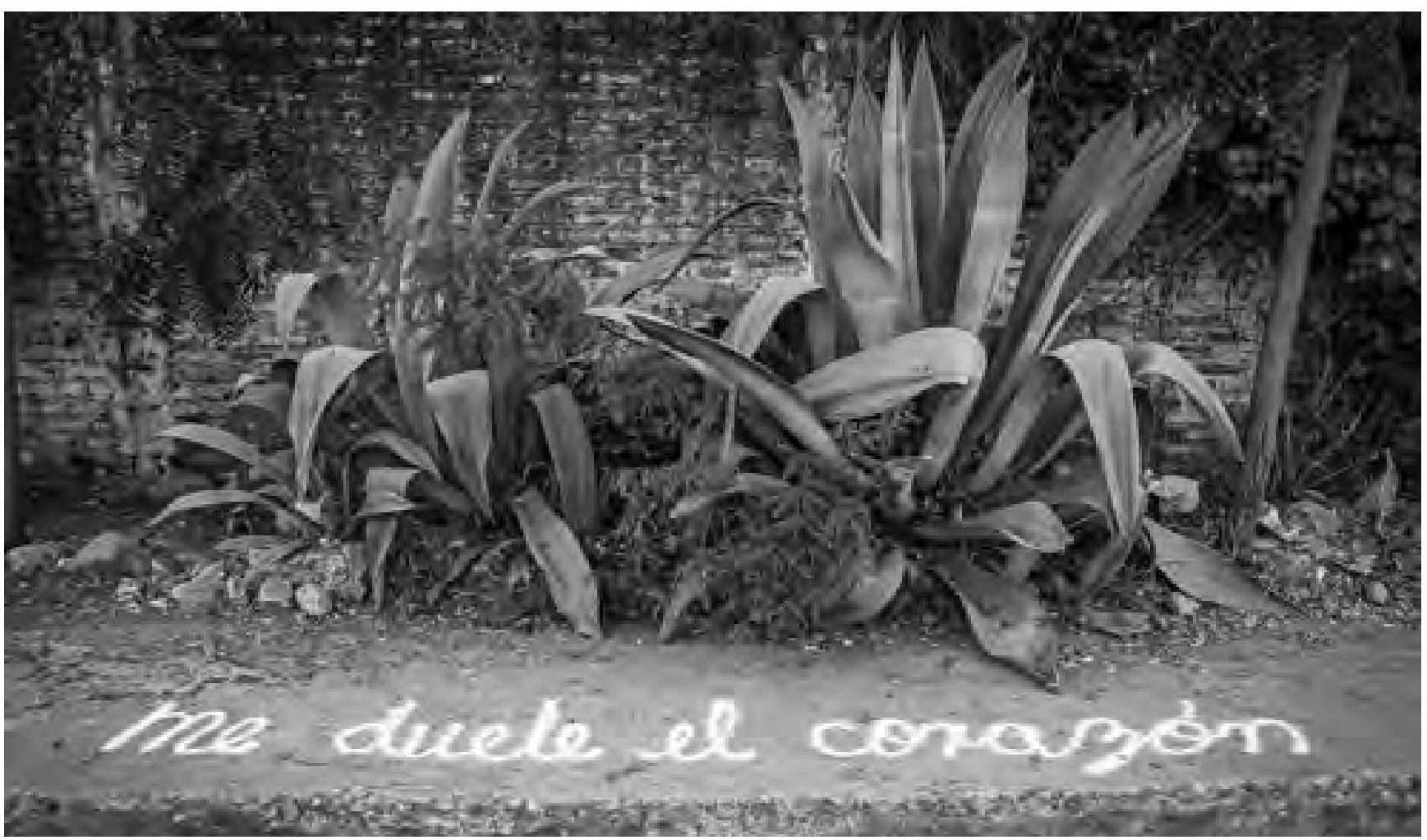

Elina Chauvet, De la serie fotográfica Lagrimas de sal, intervención en espacios públicos con sal, que representa las lágrimas de las madres y familiares de desaparecidos, fotografía digital, 2015.

años, aliados pragmáticos del gobierno de Ortega- o los partidos tradicionales.

Cuatro universidades (tres públicas y una de carácter privado) se volvieron emblemáticas -la Universidad Nacional de Ingeniería (UNI), la Universidad Nacional Autónoma de Nicaragua (UNAN) en Managua, la UNAN-León y la Universidad Politécnica (UPOLI), -, al reflejar de manera dramática las dinámicas y cambios en la confrontación con el gobierno. Experimentaron la intromisión violenta de cuerpos policiales y parapoliciales en contra de manifestantes, operaron como centros de una resistencia estudiantil que tomó las instalaciones para protegerse de la acción violenta policial, dar visibilidad a la oposición y organizar la protesta, pero que al mismo tiempo no tuvo la fuerza organizativa para impedir el ingreso y la incrustación de grupos delincuenciales en las instalaciones universitarias y los tranques construidos inicialmente por los mismos jóvenes. ${ }^{5}$ En pocas semanas los activistas estudiantiles se transformaron no sólo en actores estratégicos de la movilización en contra del gobierno, sino también en voceros destacados de una oposición heterogénea y multisectorial con débiles mecanismos de cohesión basados casi exclusivamente en el anti-orteguismo, la demanda por justicia para las víctimas de la represión y elecciones anticipadas. Como señala Harley Morales, dirigente de la Coalición Universitaria de Nicaragua (una de las coordinadoras estudiantiles que se formó al calor de la movilización), en una entrevista: "Sabemos que sólo nosotros podemos legitimar este proceso [...]. Tenemos legitimidad y esta alianza existe por nosotros, no por el sector privado, y podemos deslegitimar la alianza y salirnos" (Dada, "La prioridad ahorita es que no nos maten; luego la justicia y la democracia", 2018). Pero esta legitimidad no es sólo resultado de una coyuntura de participación estudiantil en las protestas en contra del gobierno de Ortega y Murillo, sino se apoya en la construcción de una narrativa central dentro de la cultura política nicaragüense respecto a los universitarios, y en términos más amplios los jóvenes, como actores clave de la política nicaragüense, desde la lucha en contra de la dictadura familiar de los Somoza (que dominaron el país de 1933 a 1979, hasta su participación en el proceso revolucionario de la década de 1980, que el partido gobernante FSLN reivindica como su legado histórico). 


\section{La politización de las universidades}

La representación de los universitarios como fuerza crítica al estatus quo forma parte del imaginario político de la sociedad nicaragüense (como en general de las sociedades latinoamericanas). Como en el resto de Centroamérica, a mediados del siglo veinte las universidades comenzaron a crecer en términos de matrícula y de funcionar como espacios para la politización de activistas estudiantiles, inspirados en el movimiento de reforma universitaria de Córdoba (1918), que combinaban la lucha por las reivindicaciones universitarias -autonomía, autogobierno y participación estudiantil en los gremios colegiados- con la crítica a los actores políticos tradicionales y sus estrategias de negociación y arreglo político. En este sentido, la obtención de la autonomía académica, administrativa y económica por la Universidad Nacional de León en 1958 se enmarcó en un escenario regional conflictivo y politizado, que se caracterizaba por la movilización social y la confrontación política, como fueron la intervención militar estadounidense en contra del gobierno de Jacobo Árbenz en Guatemala en 1954, la revolución cubana de 1959 y la fundación en 1961 del FSLN que seguía el ejemplo del Movimiento 26 de julio para emprender la lucha armada en contra de la dictadura de los Somoza.

\section{La fragilidad del orden político} e institucional de Nicaragua tiene una de sus principales razones en la ausencia de consensos sociales integradores, compartidos y puestos en práctica por los principales actores sociopolíticos.

Las movilizaciones estudiantiles se desarrollaron dentro de estas lógicas de radicalización: así, el 23 de julio de 1959, en una marcha en León para denunciar la matanza de un grupo de jóvenes antisomocistas emboscados en El Chaparral (frontera con Honduras) por miembros del Ejército Hondureño y la Guardia Nacional, el choque con las fuerzas del orden terminó en el asesinato de cuatro estudiantes, una mujer, un niño y unos 80 heridos (Rocha J., 2018). Desde este momento, la identidad antidictatorial y antisomocista del movimiento estudiantil estaba definida -convirtiéndose el 23 de julio incluso en el día nacional del estudiante-, y la Universidad Nacional se transformó en un espacio en disputa entre las diferentes organizaciones políticas. Una de ellas era el Frente Estudiantil Revolucionario (FER), brazo estudiantil del FSLN, que en 1969 logró tomar el control sobre el Centro Universitario de la Universidad Nacional (CUUN), instancia representativa de todo el estudiantado.

En este mismo contexto se fundó la Universidad Centroamericana (UCA) con sede en Managua, primera universidad privada de Nicaragua y dirigida por la Compañía de Jesús. Si bien sus fundadores no pensaron admitir la organización estudiantil, fueron incapaces de mantener la institución al margen de las tendencias políticas de la época. Así, durante los años sesenta el Centro Estudiantil Universitario de la UCA (CEUUCA) se volvió un espacio de convergencia entre colectivos socialcristianos y sandinistas, que en su lucha antisomocista lograron estrechar vínculos con el movimiento estudiantil de la Universidad Nacional en León, al margen y a pesar de las autoridades universitarias de ambas instituciones. Pero cabe señalar que en esta época también ya se prefiguraron algunas de las fricciones y tensiones que caracterizaría la relación entre las dos instituciones universitarias más relevantes del país ${ }^{6}$ (El Nuevo Diario, 2010).

Después del triunfo revolucionario en 1979, se consolidó la hegemonía del FSLN dentro del movimiento universitario por medio de vías formales e informales: por una parte, la legitimidad que había adquirido el FSLN a través de la lucha antidictatorial le permitió moldear una nueva institucionalidad universitaria de acuerdo a su proyecto político-ideológico. Esto se expresó, por ejemplo, en la decisión de los diversos colectivos estudiantiles en el 8vo Congreso estudiantil en 1981, de disolverse en la recién creada Unión Nacional de Estudiantes Nicaragüenses (UNEN), pensada como una sola organización "que debía representar a todos los estudiantes" (Anfruns, 2018). UNEN, que desde sus inicios estaba dominada por líderes estudiantiles provenientes de la FER o vinculados a la Juventud Sandinista 19 de Julio, se incorporó a las instancias 
de autogobierno universitario, al igual como sucedió con los gremios de docentes y trabajadores de las universidades, que se alinearon con las otras organizaciones de masa creadas por el FSLN. Por otra parte, el gobierno revolucionario decidió en 1982 crear la UNAN-Managua y formar una instancia específica, el Consejo Nacional de Educación Superior, conformado por todas las instituciones públicas y privadas de educación superior, cuyo mandato explícito era coadyuvar a la armonización de la enseñanza superior con los objetivos del proceso revolucionario (Tunnerman Bernheim, 2008, pág. 343).

En otras palabras, las diversas estrategias de movilización, reclutamiento y construcción de instituciones permitieron al sandinismo ampliar su influencia en las universidades públicas (y en menor grado en universidades privadas como la UCA), creándose vínculos, basados en afinidades ideológicas y lazos afectivos a partir de las experiencias compartidas de la militancia, entre partido, espacio burocrático-estatal y las instituciones universitarias. Precisamente esta situación contribuyó a que las diferencias y disputas ideológicas que emergieron en el sandinismo después de su salida del gobierno en 1990 tuvieron repercusiones en el campo académico: mientras a la UNAN se solía identificar como cercana a las posturas del FSLN, en la UCA convergían académicos e intelectuales con una mayor simpatía para las corrientes disidentes del sandinismo, como el Movimiento Renovador Sandinista (MRS). ${ }^{7}$

Durante los gobiernos neoliberales (1990 a 2006), el FSLN se volvió un aliado importante de las universidades y del movimiento estudiantil en la Asamblea Legislativa para consolidar la autonomía universitaria y garantizar el presupuesto. Por ejemplo, la Ley 89 de Autonomía de las Instituciones de Educación Superior, fue presentada en 1990 por el saliente gobierno sandinista ante la Asamblea Nacional para decretar el derecho al 6 por ciento del presupuesto nacional para las universidades, reestablecer la completa autonomía universitaria y crear el Consejo Nacional Universitario, como ente coordinador y regulador de las políticas de educación superior, conformado por los rectores de las diez universidades que reciben subsidio del Estado (públicas y privadas), el presidente de UNEN y los secretarios generales de la Asociación de Trabajadores Docentes y de la Asociación de Trabajadores Universitarios (Tunnerman Bernheim, 2008, págs. 347-348). Elevado a rango constitucional en 1995, año con año la bancada sandinista apoyó a las universidades y al

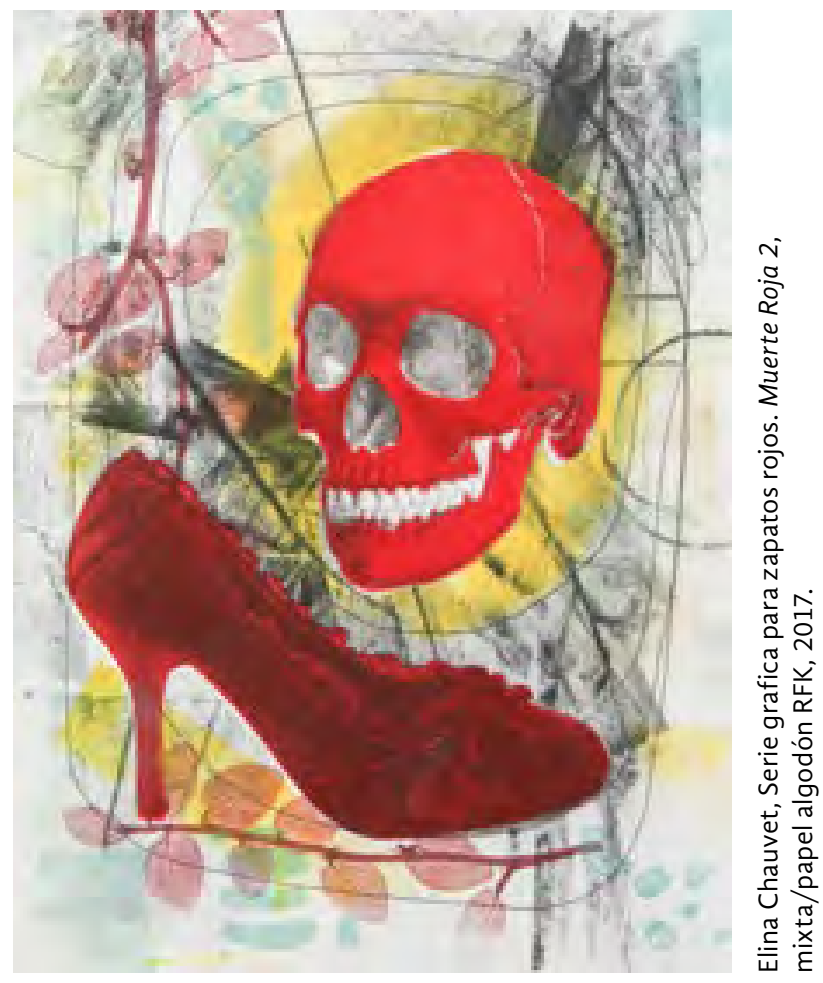


movimiento estudiantil en su demanda por asignar un 6 por ciento del presupuesto a la educación superior en un escenario económico y político de políticas de ajuste estructural. En las manifestaciones, la confrontación violenta con las fuerzas policiales era recurrente y en diciembre de 1995 incluso se produjo el primer muerto. Para el FSLN, el vínculo con las bases movilizadas del estudiantado a través de UNEN -como era el caso con otros movimientos sectoriales en el ámbito obrero, campesino y popular- le permitió afianzar su imagen como la única fuerza partidista crítica a las políticas neoliberales y comprometida con la resistencia popular, lo cual sin duda contribuyó a la victoria electoral de Daniel Ortega en el 2006 (Close, 2005, págs. 161-162).

\section{El "Poder Ciudadano" y las universidades: aciertos y tensiones}

La fragilidad del orden político e institucional de Nicaragua tiene una de sus principales razones en la ausencia de consensos sociales integradores, compartidos y puestos en práctica por los principales actores sociopolíticos. Con la revolución de 1979 estos desacuerdos sobre un conjunto básico de principios y valores para posibilitar la convivencia no violenta y el reconocimiento del otro se organizaron en torno al binomio sandinismo-antisandinismo, como dos polos que estructuran no sólo las contiendas electorales, sino también los conflictos ideológicos que atraviesan la sociedad hasta el día de hoy (Close, 2005, págs. 20-21; Pérez-Baltodano, 2013, pág. 67). En vez de consensos incluyentes, han operado, por una parte, los acuerdos personalistas entre líderes para distribuir cuotas de influencia (y excluir a adversarios políticos), como sucedió en las negociaciones de 1998 y 2000 entre Daniel Ortega y el entonces presidente Arnoldo Alemán (conocidas como el "Pacto") para determinar la composición partidista de las instancias electorales y judiciales, y la reforma electoral que permitiría reducir el porcentaje mínimo de votos necesarios para ganar la presidencia. Por otra parte, con el regreso al poder del FSLN y Daniel Ortega en el 2006, inició también un creciente proceso de centralización de poder en el Ejecutivo. El Plan Nacional de Desarrollo 2008, documento programático del primer gobierno de Daniel Ortega y del FSLN, planteaba la introducción de un 
nuevo modelo de gestión pública y toma de decisiones, denominado Poder Ciudadano, orientado hacia el fortalecimiento del Estado en combinación con mecanismos de participación ciudadana (Gobierno de Reconciliación y Unidad Nacional, 2008).

La reingeniería institucional, instrumentada desde el Ejecutivo, para asegurar la continuidad de este nuevo modelo de Estado ha implicado debilitar las capacidades de control y toma de decisiones de los otros poderes del Estado (Legislativo, Judicial y Electoral), revertir la descentralización municipal y afectar la independencia profesional de instituciones clave para la gobernabilidad como las Fuerzas Armadas y la policía, señaladas por voces críticas de la administración de Ortega como actores cada vez más partidizados y comprometidos con la figura del presidente, por tanto como otro indicio más de las tendencias autoritarias del gobierno (Pérez-Baltodano, 2013, págs. 42-50). Pero también significó la implementación de programas sociales y prestaciones para el sector laboral y campesino (desde la distribución de láminas de zinc, microcréditos, organización de ferias locales para productos campesinos, becas para estudiantes de todos los niveles, hasta la obligación de los empleadores a inscribir a sus trabajadores al Seguro Social, independientemente de la duración de su contrato), lo cual permitió al gobierno de Ortega consolidar su apoyos en los sectores populares (Rocha J. L., 2016). Pero para lograr una articulación de las diferentes instancias sociales y áreas gubernamentales, condición básica para que este modelo de gestión estatal pudiera funcionar, se requería de una red de agentes sociales, comprometidos con el proyecto político-partidista y leales al presidente, y en consecuencia dispuestos a poner en práctica los mandatos del Ejecutivo.
Las universidades no han quedado al margen de estas dinámicas. El ya citado Plan Nacional de Desarrollo definió para el sector de la educación superior varias estrategias, entre ellas, elevar la calidad y pertinencia de la educación pública, ampliar su cobertura, fortalecer la institucionalidad y articulación del sector, fomentar la educación superior en la Costa Caribe y promover una cultura de rendición de cuentas que debería incluir la contribución de las universidades a la resolución de las problemáticas económicas, sociales, productivas y culturales del país, especialmente aquellas relacionadas con la pobreza. En otras palabras, la contribución a la superación de la pobreza, de acuerdo al mandato gubernamental, implicaría para el sector educativo vincularse con los "esfuerzos del Poder Ciudadano, siempre respetando la autonomía universitaria. Se trata de rescatar "el alma" de las universidades que debe ser su compromiso en contribuir al desarrollo del país en la superación de la pobreza" (Gobierno de Reconciliación y Unidad Nacional, 2008, pág. 127).

Sin pretender un regreso al modelo de la década de 1980, de subordinar la autonomía universitaria a los objetivos superiores del proceso revolucionario, la política sectorial enunciada definitivamente expresaba la pretensión de la administración sandinista de fortalecer la incidencia gubernamental, principalmente en las diez instituciones universitarias que integran el CNU y se benefician del subsidio estatal. Pero como compensación anunciaba también un mayor compromiso público con estas universidades lo cual se refleja en el incremento constante, entre 2008 y 2019, de las asignaciones presupuestarias, de 57,139,646 dólares a 159,759,058 dólares, llegando al punto más alto en el 2018 , con 173,957,360 dólares (todos los dólares son constantes de 2017). ${ }^{8}$ 
CUADRO 1.

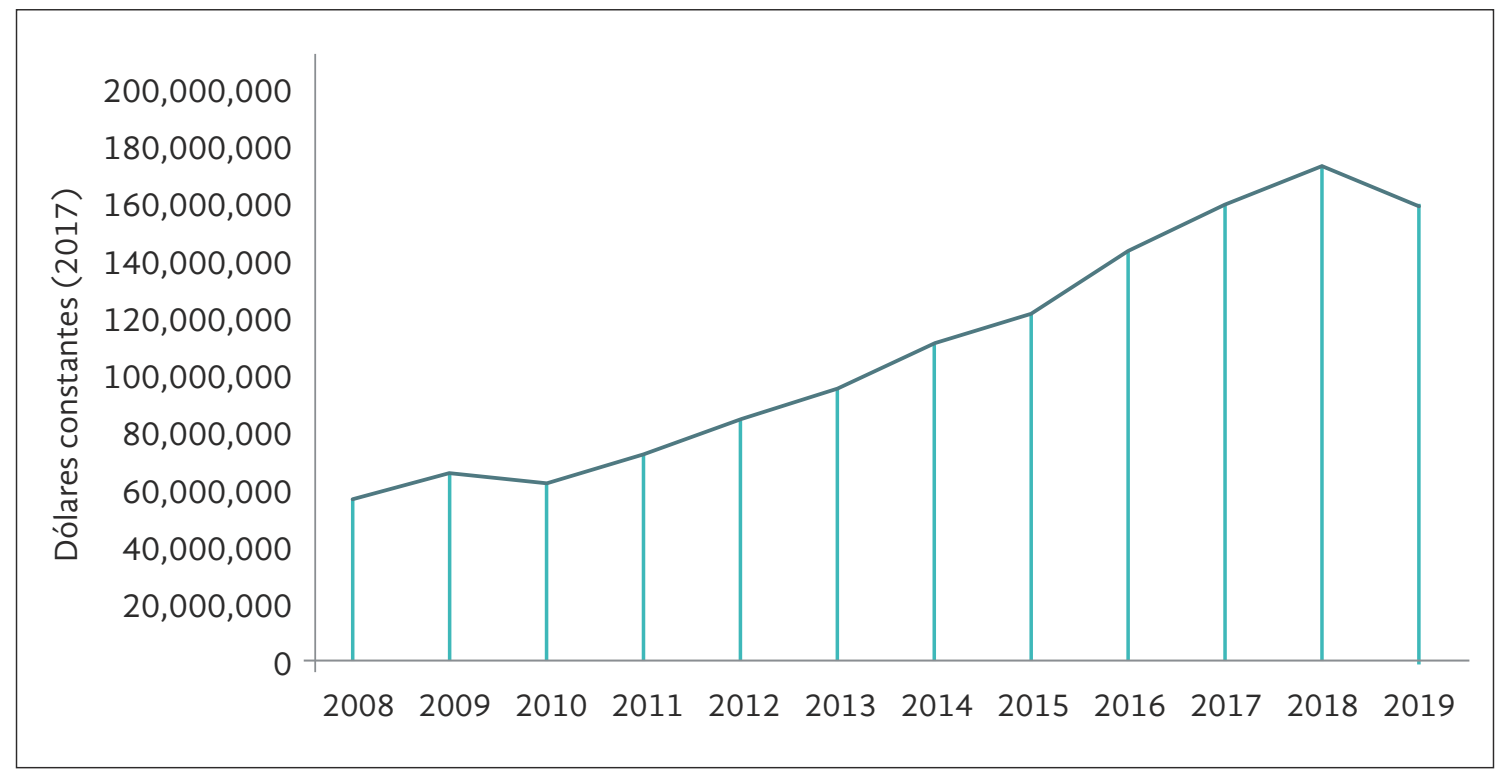

Fuente: Elaboración propia con base en datos del Ministerio de Hacienda y Crédito Público de Nicaragua, Presupuesto General de la República (2008 a 2019).

Asimismo aumentó la cantidad de estudiantes inscritos en las universidades más importantes del país: mientras en el 2007 en las universidades agrupadas en el CNU la matrícula era de 79 mil estudiantes (Gobierno de Reconciliación y Unidad Nacional, 2008, pág. 125), en el 2016 era de 120,305 estudiantes (Consejo Nacional de Universidades, 2016, pág. 10). ${ }^{9}$ Pero a pesar del incremento de presupuesto y de matrícula, no se ha logrado un impacto positivo en la superación de la desigualdad en cuanto al acceso a la educación superior. Es decir, en Nicaragua en el 2014 la proporción de personas entre 25 y 29 años con educación terciaria (cuatro años de estudios concluidos) ascendió a un 20,3 por ciento, a diferencia de, por ejemplo, Honduras donde sólo un 6,4 por ciento de las personas entre 25 y 29 cuentan con educación terciaria (datos de 2016). Pero son en su mayoría jóvenes de las clases medias y clases altas: analizando el nivel educativo por quintiles de ingreso, el 50,9 por ciento de jóvenes nicaragüenses pertenecientes al Quintil V acceden a la educación superior, pero sólo el 2,3 por ciento del Quintil I, lo cual implica una brecha educativa de 48,3 por ciento (CEPAL, 2019, pág. 193). ${ }^{10}$
En este contexto de crecimiento de la matrícula, que ha beneficiado principalmente a los jóvenes de los sectores medios (sandinistas y no sandinistas), la monopolización de la representación estudiantil en las principales universidades nacionales por colectivos afines al partido en el gobierno generó, además de apatía en una parte del estudiantado, malestar e inconformidades en otros universitarios que no comulgan ideológicamente con el FSLN y las políticas el Gobierno de Reconciliación y Unidad Nacional. Adicionalmente, algunas de las estrategias de la organización estudiantil para imponer sus decisiones y expulsar otras opciones ideológicas del espacio universitario incluían formas de acción directa como la toma de instalaciones universitarias para obtener un mayor número de becas de las autoridades (Castillo Bermúdez, 2016), o protestar en contra de la presencia de personalidades identificadas con la oposición. Así sucedió, por ejemplo, en la UNAN-León con la protesta de la dirigencia de UNEN en contra de Sergio Ramírez, en mayo de 2009, que llevó al reconocido escritor nicaragüense y crítico de Daniel Ortega, a suspender la presentación de su libro "El cielo llora 
por mí” (El Nuevo Diario, 2009). También se fueron sumando las denuncias de estudiantes disidentes respecto a manejos discrecionales en la distribución de las becas o de acceso a las residencias estudiantiles, lo cual afectaba especialmente a estudiantes de bajos recursos y sin familiares en las ciudades universitarias.

En otras palabras, si bien las protestas de abril de 2018 no estaban ligadas directamente a demandas estudiantiles o a políticas universitarias -aspecto en el cual concuerdan representantes y simpatizantes del gobierno sandinista con los líderes de la oposición estudiantil-, entre las expresiones iniciales de las protestas, al menos en las universidades nacionales, es posible reconocer que el malestar no se dirigía únicamente en contra del gobierno de Ortega y Murillo, sino de una estructura gremial que, a los ojos de muchos estudiantes, había dejado de servir al interés colectivo, sino beneficiaba a los intereses particulares de los líderes y sus colaboradores. El sociólogo estadounidense Barrington
Moore señala en uno de sus estudios sobre las bases sociales de la rebelión que las relaciones de autoridad requieren, para su reproducción, la existencia de lazos de reciprocidad entre dominantes y dominados lo cual permite la legitimación del poder (Moore, 1987, pág. 38). En el caso de la representación estudiantil, su vinculación exclusiva y excluyente con el gobierno y el FSLN había puesto en entredicho los lazos de reciprocidad, abriéndose de esta manera espacios para el cuestionamiento de la organización histórica y la emergencia de nuevos liderazgos. En este contexto, la demanda por la recuperación de la autonomía universitaria y las críticas a UNEN apuntan (también) a una reivindicación del derecho a la disidencia, en contra de estructuras de representación consideradas cada vez más corporativas, autoritarias y excluyentes, y a la indignación por los intentos de manipular la participación estudiantil a favor del FSLN, a través de prometer o negar el acceso a becas y otros beneficios escasos.

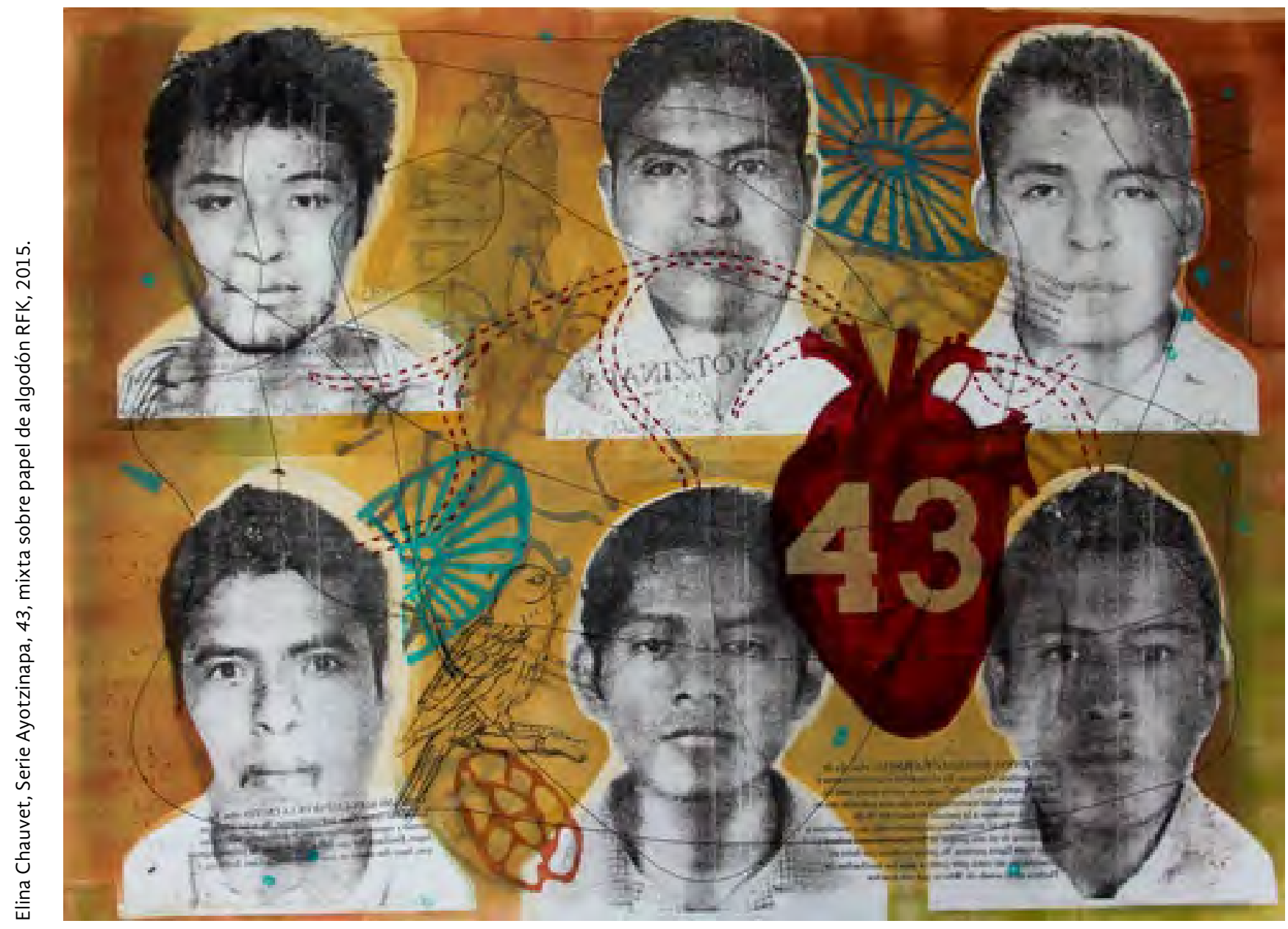




\section{Usos y significados de la violencia}

En una conversación con un estudiante nicaragüense del segundo semestre de la UNI, a quien sus padres habían enviado al extranjero para alejarlo de las situaciones de violencia que vivía el país, el adolescente, que no recordaba otro gobierno que no fuera el de Daniel Ortega, decía que antes de las protestas no se había podido imaginar "que la vida podría ser diferente, y que podría haber una Nicaragua sin Daniel Ortega". Ahora compartía la misma sensación de urgencia, expresada en los discursos de Lester Alemán y otros líderes estudiantiles que Ortega tenía que renunciar al gobierno de manera inmediata. El estudiante tuvo que salir del país por las amenazas que recibía a raíz de su participación en las marchas de oposición, especialmente en la marcha de las madres, del 30 de mayo de 2018. Pero lo sorprendente de su relato fue que, según él, estas amenazas no provenían de agentes gubernamentales, sino de familiares suyos que seguían apoyando al gobierno de Ortega y Murillo.

Durante las protestas, la disputa por el control de los espacios ha sido clave, como permite ver la reconstrucción de las dinámicas de la violencia colectiva en algunos casos emblemáticos.

Este ejemplo da cuenta del fenómeno alarmante de polarización que las fotos de policías represivos y jóvenes heridos no permiten ver, y que los informes de los organismos internacionales de derechos humanos no han retomado en su justa medida: Las divisiones entre sandinismo y anti-sandinismo, presentes en la sociedad nicaragüense desde la revolución de 1979 afloraron durante la crisis política e imprimieron una lógica ideológica a muchos de los actos violentos que cobraron víctimas tanto del lado de los manifestantes antigubernamentales, como del lado sandinista. Por tanto, también las inconformidades surgidas en las universidades a raíz de la injerencia estatal y la centralidad de UNEN, percibidas como socavamiento de la autonomía universitaria, se fueron articulando con los principios de oposición ideológica sandinismoantisandinismo. Es bajo esta lógica que se debe interpretar la violencia en contra de activistas estudiantiles sandinistas, ocurridos en el contexto de las protestas. Las dos víctimas más emblemáticos de la violencia antisandinista en el ámbito universitario, fueron la muerte de Cristian Cadenas, estudiante de ingeniería agroecológica y activista de UNEN en León, el 20 de abril en el contexto de la incineración del local de UNEN conocido como "Casa CUUN", y el secuestro y tortura de Leonel Morales, dirigente de UNEN en la UPOLI y participante en el Diálogo Nacional como parte de la delegación gubernamental (Telesur, 2018; Anfruns, 2018), el 14 de junio.

Los sentimientos anti-sandinistas que están presentes en un segmento importante de la resistencia estudiantil, se reflejan también en la construcción de las alianzas políticas nacionales e internacionales. En Nicaragua, el obispo auxiliar de Managua Silvio Báez -crítico del FSLN y de Daniel Ortega desde antes del estallido de las protestas- se volvió una figura clave para asesorar a los estudiantes incidiendo de manera directa en los procesos de elección de representantes para la mesa del diálogo nacional convocada por la iglesia en mayo (Dada, 2018a). Así mismo, los estudiantes fueron respaldados por sectores empresariales que apoyaron económicamente la incipiente organización estudiantil, con el propósito de construir lealtades de cara a las negociaciones con el gobierno. En el ámbito internacional, líderes estudiantiles como Víctor Cuadra del Movimiento 19 de abril, se reunieron con representantes del ala derechista del Partido Republicano en Washington, así como con el partido Alianza Republicana Nacionalista (ARENA) en El Salvador, lo cual aprovechó el gobierno nicaragüense para apuntar una vez más hacía la injerencia extranjera y los intereses partidistas de la oposición nicaragüense que estarían manipulando las protestas para derrumbar al gobierno (Dada, 2018). 
Pero más allá de las sospechas gubernamentales, había indicios en la violencia anti-gubernamental que daban cuenta de la disposición ideológica subyacente. En los acontecimientos ocurridos en León, segunda ciudad más importante después de Managua, es posible reconstruir como el descontento estudiantil se fue combinando con la lógica polarizante de la disputa ideológica, desembocando en el incendio del local histórico de UNEN, primero, y de Radio Darío, una radio local opositora, después. Entre las razones por la radicalización y el incremento de las protestas entre el 17 y 18 de abril, señalados por activistas estudiantiles, se encuentra la intervención de grupos de choque sandinistas en las marchas en contra de la reforma del INSS. A la indignación por el acoso se fueron sumando los rumores -transmitidos a través de las redes sociales- que a los estudiantes que vivían en las residencias estudiantiles se les iba a obligar a participar en movilizaciones a favor del gobierno, lo cual condujo a que varios estudiantes se salieron de las residencias para buscar refugio en casas particulares en la ciudad. El 20 de abril, después de una movilización pacífica que fue dispersada violentamente por los antimotines provenientes de Managua, una parte de los manifestantes se dirigió hacia la Casa CUUN que fue saqueada e incendiada. En el edificio contiguo a la Casa CUUN, afectado igualmente por el incendio, se encontró posteriormente el cuerpo calcinado del activista estudiantil Cristian Cadenas. Este mismo día en León, simpatizantes del gobierno quemaron Radio Darío, radioemisora vinculada históricamente a la oposición anti-sandinista. Murieron dos manifestantes, supuestamente a raíz del manejo de la gasolina usada para incendiar la radio (Grupo Interdisciplinario de Expertos Independientes Nicaragua, 2018, págs. 90-91).

Durante las protestas, la disputa por el control de los espacios ha sido clave, como permite ver la reconstrucción de las dinámicas de la violencia colectiva en algunos casos emblemáticos. Fueron universidades específicas -el 19 y 20 de abril la UNI, del 19 de abril hasta el 30 de mayo la UPOLI y durante mayo y junio la UNAN-Managua-, que se volvieron puntos de referencia para un activismo juvenil que, si bien resaltaba la dimensión estudiantil, era mucho más heterogéneo y multifacético debido a la convergencia de estudiantes universitarios, con alumnos de secundaria, y jóvenes 
de los barrios marginales de Managua. Esta dinámica apenas empezó a notarse en la toma de la UNI, los días 19 y 20 de abril de 2018, que fue desarticulada por el ingreso violento de los cuerpos policiales el 20 de abril. La combinación de la toma de las instalaciones universitarias, para evitar el ingreso de la policía, las marchas provenientes de otras universidades (especialmente de la UCA y la UNAN) que se acercaban a pesar de los cercos policiales, los ataques de francotiradores en los alrededores de la universidad y la llegada de jóvenes de barrios aledaños para enfrentarse a la policía, contribuyó a la escalada del enfrentamiento que produjo víctimas fatales, entre ellos la muerte del estudiante de secundaria Álvaro Conrado Dávila, la víctima más joven de la acción policial, que se volvería emblemática para el movimiento de protesta. El joven recibió dos impactos de balas de goma, una en el cuello (Grupo Interdisciplinario de Expertos Independientes Nicaragua, 2018, pág. 118; Comisíon Interamericana de Derechos Humanos, 2018, pág. 14). Sus palabras "me duele respirar" se transformaron en una consigna del movimiento estudiantil para expresar su repudio a un gobierno que no asumía la responsabilidad para el accionar violento y desmedido de sus cuerpos de seguridad.

Con el cierre de la UNI, después de los acontecimientos del 20 de abril, la UPOLI, universidad privada que recibe subsidios públicos y forma parte del CNU, se convirtió en el centro de convergencia de estudiantes provenientes de diferentes universidades de la capital. También fue un lugar donde las confrontaciones cobraron más víctimas -16 muertos hasta el 30 de mayo- posiblemente por las características de la zona. El Distrito VI pertenece a las zonas con la mayor concentración de pobreza y el mayor índice de delitos y narcomenudeo de Managua, que cuenta con una presencia importante de pandillas juveniles (Instituto de Estudios Estratégicos y Políticas Públicas, s/f; Policía Nacional, 2017). Fue con el apoyo directo de los jóvenes marginales de la zona que los estudiantes de la UPOLI lograron atrincherarse en las instalaciones de la universidad y repelar los ataques policiales y de los grupos de choque. Pero esta alianza también implicó que, en un contexto de reflujo de la movilización, la presencia estudiantil en las instalaciones disminuyó y las pandillas ejercieron cada vez más el control, utilizándolas como un centro de operación para realizar acciones delictivas. La ocupación terminó formalmente el 9 de junio por medio de un operativo policial en contra de las pandillas juveniles, pero desde el 30 de mayo, como señala el periodista Carlos Dada de la revista digital El Faro, los "tiempos" de la UPOLI como centro de la movilización estudiantil ya habían terminado desde mucho antes (2018a)

\section{Los sentimientos anti-sandinistas que están presentes en un segmento importante de la resistencia estudiantil, se reflejan también en la construcción de las alianzas políticas nacionales e internacionales.}

El último caso de toma de una universidad fue la ocupación de la UNAN-Managua entre el 7 y 8 de mayo, en un momento de descenso de la movilización estudiantil y el desplazamiento de la acción directa de los manifestantes hacía los tranques en la vía pública. También en este caso es posible observar la articulación entre el cuestionamiento estudiantil a la representatividad de UNEN, la solidaridad con las víctimas de la violencia policial y la demanda por la renuncia de Daniel Ortega y Rosario Murillo. El 7 de mayo, una movilización de estudiantes y docentes, vestidos de negro y con la bandera nacional azul y blanco, bajo el nombre "Movimiento Universitario UNAN Managua", formularon demandas y denuncias, entre ellas, la reestructuración de la dirigencia de UNEN, el fin de la impunidad y de la violencia ejercida por policías, paramilitares e integrantes de la Juventud Sandinista (Velazquez \& García , 2018). Según algunos testimonios, una vez cerrado el Recinto Rubén Darío por los estudiantes empezaron a llegar camionetas con provisiones de alimentos y bebidas, así como personas no pertenecientes a la universidad que apoyaron en las 
tareas de reforzar el control de los puntos de seguridad $\mathrm{y}$ de ingreso para prevenir los ataques de las fuerzas de seguridad.

El 14 de julio, la UNAN fue "retomada" por un grupo armado del FSLN, que se enfrentó a los ocupantes del recinto. Según la fiscalía, el último grupo en abandonar la Universidad buscó refugio, primero, en la Iglesia Divina Misericordia y después en la Catedral de Managua. Pero la coyuntura ya había cambiado, Daniel Ortega había logrado recuperar el control sobre el país y la Iglesia Católica, al inicio aliado clave de los manifestantes para exigir la renuncia del gobierno, por indicaciones del Vaticano tuvo que moderar su posición. Así que las iglesias esta vez permanecieron cerradas, los jóvenes fueron capturados y entregados a la policía.

\section{Conclusiones provisionales y una hipótesis}

A casi un año del estallido de las protestas, todo parece indicar que el gobierno y el FSLN han recuperado el control sobre las calles y los espacios públicos, y aceptaron un nuevo proceso de Diálogo Nacional con la coalición opositora Alianza Cívica, acompañado por el nuncio apostólico Mons. Waldemar Sommertag y Luis Ángel Rosadilla, representante de la secretaría general de la OEA. Entre los primeros compromisos acordados está la liberación de todos los presos políticos y el reconocimiento a las libertades ciudadanas por parte del Estado. Las universidades, por su parte, aseguran haber iniciado el semestre sin contratiempos, aunque con mayores medidas de seguridad y control porque, de acuerdo con la rectora de la UNAN-Managua Mtra. Romana Rodríguez en una entrevista radical en enero de 2019, "no podemos hacer más de lo mismo". Con esta frase hace referencia no sólo a la reducción de las asignaciones presupuestarias, consecuencia inmediata de la disminución de los ingresos públicos, y a las pérdidas materiales, resultado de la destrucción de edificios y robo de equipamiento técnico y laboratorios, y que en el caso de la UNAN-Managua asciende a 15 millones de U\$. También hace referencia a un necesario "cambio de cultura" en cuanto a la seguridad y el acceso a las instalaciones universitarias para prevenir el ingreso a personas ajenas y alejar la delincuencia y el vandalismo de la universidad (Consejo Nacional de Universidades, 2019). Para los críticos a los nuevos dispositivos oficiales de control, se trata de medidas para evitar futuras protestas y una reactivación del estudiantado disidente.

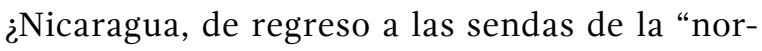
malidad"? El panorama es incierto y los constantes cambios en las dinámicas de la negociación política dificultan formular una respuesta concluyente al respecto. En el caso de los universitarios, las lógicas de la protesta social en interacción con la violencia policial y parapolicial, que nos propusimos examinar en este trabajo, nos llevaron a identificar el malestar de un importante segmento estudiantil con una representación gremial identificada con una sola fuerza partidista, como un factor que nutrió la protesta social que trascendió las afectaciones universitarias para dirigirse en contra del gobierno del FSLN. Pero este hallazgo implica también ir más allá de una lectura esquemática que resalta como único eje explicativo la confrontación entre un Estado autoritario y las reivindicaciones democráticas de diversos actores sociales. Más bien hay que tomar en cuenta que la violencia ejercida a nivel social apunta a la confrontación entre dos imaginarios opuestos y excluyentes entre sí que han orientado las estrategias de acción gubernamentales, partidarios y de los manifestantes. 


\section{Notas}

1. Además de las fuentes citadas, este artículo se basa en entrevistas y conversaciones informales con colegas y amigos nicaragüenses (algunos con simpatías hacía el FSLN y otros hacía la oposición), en torno a las causas, dinámicas y actores de la crisis política que experimenta el país desde abril de 2018. Quiero agradecer la información y los claves de análisis que ellos aportaron para la elaboración del artículo. Por razones de confidencialidad no se mencionan sus nombres.

2. El Fondo Monetario Internacional (FMI) había planteado la necesidad de una reforma al Seguro Social para evitar el colapso financiero del sistema de retiro proponiendo la elevación de la edad de retiro de 60 a 65 años, y duplicar las semanas de cotización para jubilarse de 750 a 1500 semanas. También propugnaba por eliminar las pensiones para las víctimas de la guerra de la década de 1980, algunas asignaciones a los ancianos y programas de atención médica a pensionados como las de oncología y de hemodiálisis. El empresariado se inclinaba a favor de esta propuesta. El gobierno, en cambio, propuso una reforma que contó con el aval del sindicalismo agrupado en el Frente Nacional de Trabajadores (FNT) y cercano al FSLN, en la cual se planteó mantener las pensiones para víctimas de la guerra, aumentar gradualmente el incremento de la participación de las empresas al sistema de seguridad, de 19 a 22,5 por ciento, y de los trabajadores de 6,25 a 7 por ciento. Los pensionados aportarían con un 5 por ciento de sus pensiones a la sustentabilidad del sistema para destinarlo a la asistencia médica. Con el argumento que las medidas iban a afectar el empleo COSEP se retiró de las negociaciones, por lo cual el gobierno decidió publicar la reforma. Los medios de comunicación de la oposición cuestionaron desde un principio la reforma por ser, según ellos, inviable para rescatar al Seguro Social y por implicar un descuento a las jubilaciones (Castro Iraheta, 2018, pág. 175).

3. Ejemplo de esta lectura es el Informe del Grupo Interdisciplinario de Expertos Independientes (GIEI) (Grupo Interdisciplinario de Expertos Independientes Nicaragua, 2018).

4. En Nicaragua los "tranques" hacen referencia a las barricadas que construyeron los manifestantes en barrios y la vía pública para impedir el avance a las fuerzas policiales y antimotines. En muchos lugares fueron ocupados por los grupos más radicales de la oposición anti-sandinista y pandilleros que exigían peaje o asaltaban a las personas que tenían que pasar por estas barricadas. A partir de junio, las muertes se produjeron principalmente en el contexto de los tranques en confrontaciones entre "tranqueros" y miembros del FSLN y de la Juventud Sandinista que pretendían remover los obstáculos.

5. El caso de la UPOLI es emblemático en este sentido porque en el transcurso de mayo de 2018, jóvenes marginales que llegaron a la universidad inicialmente para apoyar a los estudiantes en la toma de la universidad en contra de las fuerzas del orden, terminaron por marginar a los estudiantes y ocupar las instalaciones hasta la recuperación por parte de la policía (profundizaremos sobre este aspecto más adelante). En el caso de León, un comunicado de la organización estudiantil M19 de abril también permite aprehender las dinámicas de la alianza estudiantes-jóvenes marginales que en un cierto momento se volvió contraproducente para el movimiento de protesta: "El Movimiento 19 de Abril de León, expresa a la población leonesa sus más sinceras disculpas por las agresiones e inconformidades presentadas en los últimos tranques (...) En nuestra etapa de vulnerabilidad, invitamos y aceptamos ayuda de diferentes sectores del pueblo, porque necesitamos unión, depositamos mucha confianza en ellos, por lo cual omitimos tomar acciones de control, lo que provoco [sic.] inestabilidad y falta de credibilidad en el movimiento."

6. En 1963 las autoridades de la UNAN pretendieron imponer que los exámenes de graduación de la UCA se realizaran en sus instalaciones en León. A raíz de la protesta estudiantil Mariano Fiallos, entonces rector de la UNAN, se vio obligado a retirar esta propuesta (El Nuevo Diario, 2010).

7. Entre 1994 y 1998 se desarrolló un importante debate al interior del FSLN para (re)definir el proyecto político del FSLN -revolucionario o reformista-, y los principios organizativos -participativos-democráticos o verticalistas- que el partido debería adoptar para regular la vida interna. El conflicto produjo la escisión hasta ahora más relevante del sandinismo con la formación del MRS en 1995 dirigido en este momento por el escritor Sergio Ramírez y Dora María Téllez. Actualmente entre sus portavoces más importantes se encuentran Dora María Téllez, Victor Hugo Tinoco, Suyen Barahona y Ana Margarita Vijil.

8. Cifras recuperadas de Ministerio de Hacienda y Crédito Público de Nicaragua, Presupuesto General de la República, Asignaciones y Subvenciones disponible en http://www.hacienda.gob.ni/ Direcciones/presupuesto/libros-presupuestarios/informacionde-los-libros/ (no se incluyen los subsidios a teléfono y electricidad de las universidades); Banco Central de Nicaragua, Tipo de Cambio Oficial Anual, disponible en https://www.bcn.gob.ni/ estadisticas/mercados_cambiarios/tipo_cambio/cordoba_dolar/cambio_historico/index.php?\&val=0

9. De un total de 120000 estudiantes de educación superior en 2007 (Gobierno de Reconciliación y Unidad Nacional, 2008, pág. 125) y 160000 en el 2016 (Otras Voces en Educación, 2018).

10. Datos corresponden a áreas urbanos. En el caso de Honduras, la brecha educativa es menor, porque es el 18.7 por ciento de jóvenes del Quintil V versus el 1,5 por ciento del Quintil I que cuentan con educación universitaria. En cuanto a Guatemala y El Salvador, el porcentaje de jóvenes con educación terciaria se asemeja a Nicaragua: 18,3 por ciento y 18,1 respectivamente, con una brecha educativa entre el Quintil I y V de 39,1 por ciento y 35.5 por ciento (CEPAL, 2019, pág. 193). 


\section{Bibliografía}

Anfruns, A. (2018 de Agosto de 2018). "En Nicaragua los universitarios han sido víctimas del terrorismo golpista" Entrevista a Luis Manuel Andino Paiz (Presidente UNEN). Recuperado de Rebelion : http:// www.rebelion.org/noticia.php?id=244794

Castillo Bermúdez, J. (2016 de febrero de 2016). Upoli cede ante las presiones de UNEN. Autoridades reconocen a UNEN "Instrumento político" del FSLN en las universidades. La Prensa, pág. 3. Recuperado el 10 de abril de 2019, de http://kiosko.gepnicaragua.com/uploads/la-prensa/2016/02/20160219/files/assets/ common/downloads/page0003.pdf

Castro Iraheta, I. (2018). Nicaragua: Comunicación y redes en la crisis. En E. Degori, A. Aguilar, \& C. Villacorta, Nicaragua en crisis (págs. 169-188). Buenos Aires: Sans Soleil Ediciones.

CEPAL. (2019). Panorama Social de América Latina 2018. Santiago de Chile: Naciones Unidas. Recuperado el 2 de marzo de 2019, de https://repositorio.cepal.org/bitstream/handle/11362/44395/11/S1900051_es.pdf

Close, D. (2005). Los años de Doña Violeta. La historia de la transición política. Managua: Lea Grupo Editorial.

Comisión de la Verdad, Justicia y Paz. (2018). Segundo Informe preliminar. Asamblea Legislativa de Nicaragua, Managua.

Comisión Interamericana de Derechos Humanos. (2018). Graves violaciones a los derechos humanos en el marco de las protestas sociales en Nicaragua. Washington: CIDH/OEA.

Consejo Nacional de Universidades. (2016). Rendición Social de Cuentas 2016. Managua.

Consejo Nacional de Universidades. (28 de enero de 2019). No podemos hacer más de lo mismo. Recuperado el 21 de febrero de 2019, de http://www.cnu.edu.ni/no-podemos-hacer-mas-de-lo-mismo/

Dada, C. (2018de Junio de 2018). "La prioridad ahorita es que no nos maten; luego la justicia y la democracia”. ElFaro.net. Recuperado de https:// elfaro.net/es/201806/centroamerica/22015/\%E2\%80\%9CLaprioridad-ahorita-es-que-no-nos-maten;-luego-la-justicia-y-lademocracia\%E2\%80\%E2\%80\%A6

Dada, C. (30 de abril de 2018a). Nicaragua: Los estudiantes buscan líderes. El Faro.net. Recuperado el 2 de abril de 2019, de https:// elfaro.net/es/201804/centroamerica/21819/Nicaragua-losestudiantes-buscan-1\%C3\%ADderes.htm

El Nuevo Diario. (27 de mayo de 2009). CUUN orteguista reitera: "Muera la inteligencia”. El Nuevo Diario. Recuperado el 27 de febrero de 2019, de https://www.elnuevodiario.com.ni/nacionales/48729cuun-orteguista-reitera-muera-inteligencia/

El Nuevo Diario. (11 de abril de 2010). Inicios del movimiento estudiantil en la UCA. El Nuevo Diario. Recuperado el 27 de febrero de 2019, de https://www.elnuevodiario.com.ni/opinion/72016inicios-movimiento-estudiantil-uca/

García-Guadilla, M., \& Mallén, A. (enero-abril de 2010). El movimiento estudiantil venezolano: narrativas, polarización social y públicos antagónicos. Cuadernos del CENDES, 27(73), 71-95.

Gobierno de Reconciliación y Unidad Nacional. (2008). Plan Nacional de Desarrollo Humano 2008-2012. Documento borrador. Managua. Recuperado de file://C:/Users/kpirker/Downloads/Plan\%20 Nacional\%20de\%20Desarrollo\%20Humano\%202008-2012-Nicaragua.pdf
Grupo Interdisciplinario de Expertos Independientes Nicaragua. (2018). Informe sobre los hechos de violencia ocurridos entre el 18 de abril y el 30 de mayo de 2018. Recuperado de www.gieinicaragua.org

Instituto de Estudios Estratégicos y Políticas Públicas. (s/f). Una mirada a las causas del delito en los Distritos IV, V, VI de Managua. Managua: IEEPP. Recuperado de https://www.ieepp.org/media/ files/publicacion-2-136.pdf

López, I. (4 de mayo de 2018). "Es una conspiración pagada por Estados Unidos”: Jacinto Suárez, secretaria de Relaciones Exteriores del Frente Sandinista de Liberación Nacional, sobre las protestas en Nicaragua. Managua. Recuperado de https://www.bbc.com/ mundo/noticias-america-latina-44004702

Moore, B. (1987). Ungerechtigkeit. Die sozialen Ursachen von Unterordnung und Widerstand. Frankfurt am Main: Suhrkamp.

Otras Voces en Educación. (4 de marzo de 2018). Deserción Universitaria en Nicaragua. Otras Voces en Educación. América Latina. Recuperado de Otras Voces en Educación: http://otrasvoceseneducacion.org/archivos/270103

Pérez-Baltodano, A. (2013). Postsandinismo. Crónica de un diálogo intergeneracional e interpretación del pensamiento político de la Generación XXI. Managua: IHNCA-UCA.

Policía Nacional. (5 de julio de 2017). Distrito Seis de Managua preocupado por su seguridad. Recuperado el 3 de marzo de 2019, de Policía Nacional ¡A tú servicio siempre!: https://www.policia. gob.ni/?p=6999

Rocha, J. (septiembre de 2018). Las luchas universitarias en Nicaragua (1). Cómo se llegó a la masacre de estudiantes del 23 de julio de 1959. Envío. Información sobre Nicaragua y Centroamérica (438). Obtenido de http://www.envio.org.ni/articulo/5531

Rocha, J. L. (noviembre-diciembre de 2016). El Orteguismo y sus circunstancias. Claves de un éxito volátil. Nueva Sociedad(266), 156-167.

Telesur. (14 de junio de 2018). Hallan gravemente herido a joven secuestrado en Nicaragua. Recuperado el 4 de marzo de 2019, de Telesur: https://www.telesurtv.net/news/joven-leonel-morales-halladotras-secuestro-nicaragua-20180614-0003.html

Tunnerman Bernheim, C. (julio de 2008). La Educación Superior en Nicaragua. Avaliação, 13(2), 337-367.

Uzcátegui, R. (mayo-junio de 2014). Movilizaciones estudiantiles en Venezuela. Del carisma de Chávez al conflicto en redes. Nueva Sociedad(251), 153-165.

Valdivia Ortiz de Zárate, V. (2006). Lecciones de una revolución: Jaime Guzmán y los gremialistas, 1973-1980. En V. Valdivia, R. Álvarez, \& J. Pinto, Su revolución contra nuestra revolución. Izquierdas y derechas en el Chile de Pinochet (1973-1981) (págs. 49-100). Santiago de Chile: LOM Ediciones .

Velázquez, U., \& García , K. (11 de mayo de 2018). UNAN denuncia "toma ilegal" de recinto en Managua. El Nuevo Diario. Obtenido de https://www.elnuevodiario.com.ni/nacionales/463783-unandenuncia-toma-ilegal-recinto-managua/ 